\title{
Cost estimating and building information modelling (BIM) in road construction
}

\author{
Stanislav Vitasek, Josef Zak \\ Czech Technical University in Prague, Faculty of Civil Engineering, Thakurova 7, 16629 Prague 6-Dejvice, Czech Republic (both authors)
}

\begin{abstract}
BIM (Building information modelling) methodology offers a modern tool for all branches of construction. The information model proceeds throughout the life cycle of the construction work and ideally it contains all the information associated with elements in the model composition. BIM 5D presents another natural step in widening the utilization of information modelling for cost management and which thus puts BIM into practice. The paper deals with the creation of quantity takeoff and budgeting for construction works derived from an information model. Interconnection of theoretical knowledge with building practice has been implemented through cooperation with two multinational construction companies operating in the Czech market. This has concerned cooperation based on putting forward information models which can apply modern technologies for creation of the quantity takeoff and further to budgeting for construction works. Particular study has been carried out on two technically and technologically similar transport projects.
\end{abstract}

(C) 2018 The Authors. Published by Diamond Congress Ltd., Budapest University of Technology and Economics Peer-review under responsibility of the scientific committee of the Creative Construction Conference 2018.

Keywords: BIM; cost; quantity takeoff.

\section{Introduction}

Building information modelling (BIM) offers a modern tool for solving both technical and economic issues connected with a construction project. The development of information modelling as it relates to cost management has been a widely discussed topic but so far with an almost zero impact on actual practice. The topicality of embedding modern technologies and methods seeking the most efficient way of setting costs for road construction in the Czech Republic (CR) is also supported by ever growing pressure from society for accuracy and transparency on matters of costing for public construction works. In recent years there have been instigated legal claims against high prices and insufficient quality relating to new or modernized road sections. On transport construction projects contractual costs reached overcharge levels amounting to tens of percentage points and indeed there were technical errors leading to the impossibility of using roadways to the full planned intent.

The responsible public body allocating finances for all branches of infrastructure structures is the State Fund for Transportation Infrastructure (SFTI). SFTI has initiated a steady growth of finance flowing into the construction of transport infrastructure from 2015, and there has been so far the biggest increase in monetary expenditure on transportation infrastructure compared to the previous budgetary year- actually by $56 \%$. In monetary terms, from CZK 23.0 billion to CZK 35.9 billion. This highlighted a revitalization of the construction market in this segment as well as the general economic situation in the Czech Republic. Unfortunately, this trend of construction production growth then stopped, primarily due to the absence of expert opinions on the influences of structures on the living environment and how this affects the possibility of financing projects from EU financial sources. Thus, since 2016 
there has been a steady state financial support from SFTI for road construction, holding below the limit CZK 40 billion per year.

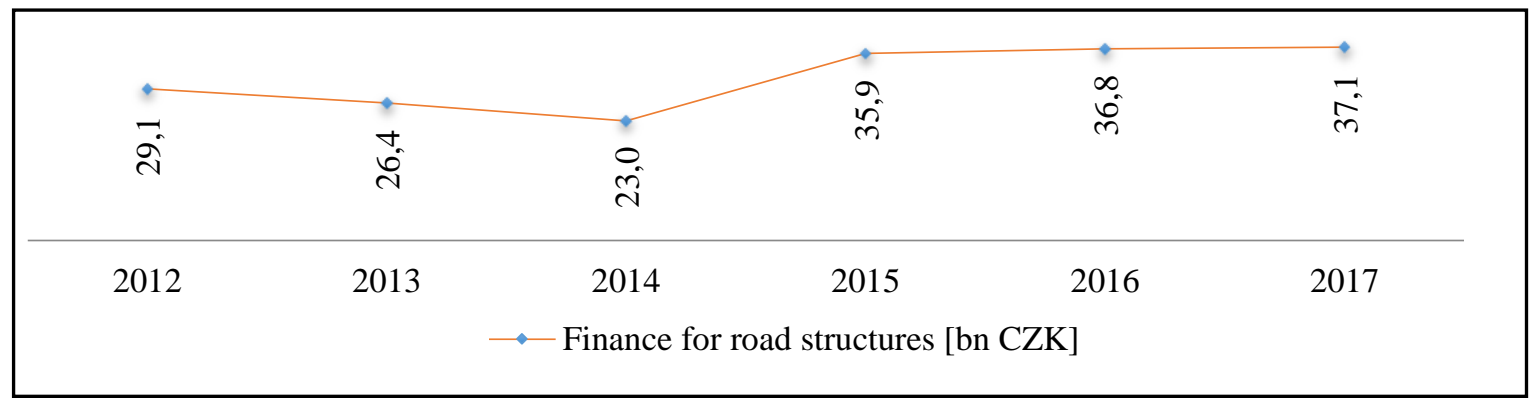

Fig. 1. Financial resources provided from SFTI for the road construction segment [1]

SFTI is integrating BIM into Czech legislation and into the actual process of transport construction. The intention of SFTI is to apply the so-called "good man's care" principle and integrate the BIM methods to the infrastructure sector in order to achieve higher efficiency. To do so a Plan for digitalization and BIM integration has been prepared by the SFTI. [2] The Czech Government Resolution No. 682 of 25 September 2017 approved the Concept of Implementation of the BIM Method in the Czech Republic, contained in Part III of Material 918/17. This document has been prepared in cooperation with SFTI. Thus the Ministry of Industry and Trade has been entrusted by the Office for Standards, Metrology and Testing (UNMZ) with the prospective intention to use its newly established contributory organization, the Czech Agency for Standardization (CAS), for the implementation of the Government approved measures mentioned in the Concept of Implementation of the BIM Method in the Czech Republic. [3]

The readiness of the construction sector for new modern methods in construction project assignment and procurement will start with testing on three pilot road projects:

- Improvement of a cross-road on roads I/32 and II/125 at the exit 42 of D11 highway - rebuilding into a roundabout;

- D1 Modernization - section 04, EXIT 34 Ostředek - EXIT 41 Šternov - flyover No. D1-040;

- I/42 Brno VMO Žabovřeská I, stage I.

In the view of the public contracting authority, the first structure where the information model (IM) will be used for the selection of the contractor is the building project I/42 in Brno, and the anticipated report on all procedures and work with the information model by both parties (public contracting authority/ contractor) will be made public by the end of 2019.

\subsection{Literature review}

In recent years the topic of BIM implementation for the construction sector has frequently been raised in scientific journals and publications. Articles usually focus on the general advantages of using information modelling in the life cycle of construction work, with a stress on increasing attention during the design proposal stage where it is possible to significantly influence future costs for repair and maintenance [4,5]. The actual inter-linkage of information modelling to other parts of cost management is a topic unfortunately not that much discussed.

As an example there is the idea to embed BIM 5D in the process of a construction project „BIM and its allied digital technologies and tools provide enormous opportunities for project cost management professionals to dramatically improve the quality, speed, accuracy, value and sophistication of their cost management services and therein ensure their future as key players in the BIM Word " where the author states that there must be developed a more determined propagation of the advantages of BIM 5D use in building projects, thus persuading investors to finance this modern technology and require it from a potential project supplier. [6] In the CR the dissemination of BIM is mostly overseen by private sector multinational companies which operate in this market area and they are significantly supported usually by owners in western developed economies who have practical experience with information modelling.

The author Jiang Xu proffers an interesting view of BIM 5D use in construction in the article Research on Application of BIM 5D Technology in the Central Grand Project. In the article Jiang Xu focuses on BIM application 
advantages on the particular project of the Central Grand project. It concerns the description of involving an information model with the process of a real project in a limited form and more likely for secondary impacts. [7] Conclusions of this research are closely monitored for likely possible application in the CR, for example on the above mentioned pilot projects.

Japanese colleagues have done detailed work on BIM use for improving infrastructure project design on designbid-build contracts. The authors affirm the economic-technical contributions of BIM at different stages of the life cycle with this type of contract. The important conclusion of this work is the necessity of gaining some essential experience before any comprehensive embedding of BIM in the public sector. [8] SFTI has been trying to carry out similar studies applicable to a specifically Czech context but so far with poor results. Public agencies have also been blamed for long term inactivity in this kind of information modelling development.

Another publication deals with a particular part of BIM 5D, namely the automated and semi-automated creation of the quantity takeoff gained from an information model. The main idea of the whole article is „The current system of estimating price in construction companies is highly labour-intensive and there is much room for error. Making quantity takeoffs from $2 D$ documentation, which is still very common, is obsolete when compared to modern tools. " The authors present advantages of using modern tools in an information model, compared to traditional 2D techniques. Unfortunately, they failed to establish in actual practice the way to apply generated data from the information model to the creation of the quantity takeoff. [9] A similar topic which concerns taking into consideration local conventions with the creation of the quantity takeoff in connection with BIM 5D, appears the most frequently. Predominantly, authors point to the fact of the impossibility of creating a fully-fledged quantity takeoff from the information model. [10,11]

From the given overview of the professional literature we unfortunately do not perceive an increased interest in the actual creation of the 3D model, where in its graphic and non-graphic detail it significantly influences possibilities of embedding 5D into the whole project process. From our viewpoint this has been caused by the reality that specialists in cost management have not yet fully appreciated the actual creation of the information model with a sense of how the originator sees it, and thus they remain unaware of current possibilities. The article "Evaluation of Maturity of BIM Tools across Different Software Platforms " describes these possibilities and assesses different software tools applicable in the BIM context. [12]

Mobile technology has also become a familiar sight on construction sites, "with smart phones and tablets being linked to the Common Data Environment. This access to the coordinated model, drawings and other project documentation improves the quality of work, reducing rework and time spent looking for information. The devices are currently also used to produce paperless quality documentation, carry out site inspections, mark-up drawings and keep site progress records. The move towards paperless documentation has created efficiencies in administrative processes, and also created data that can be used to drive." [13] In concluding this overview of the professional literature we can state that the BIM method is without exception, the correct way forward in construction activity. Primarily it relates to effective administration of a building project across the life cycle.

\section{Assessment of construction production for over-ground road communications - BIM 5D}

BIM (Building information modelling) methodology offers a modern tool for all branches of construction. The information model proceeds throughout the life cycle of the construction work and ideally it contains all the information associated with elements in model composition. BIM 5D presents another natural step to widen the utilization of information modelling for cost management and which puts BIM into practice. The possibility of connecting these two professional areas is currently a much discussed topic both with consultancy firms and with contractors. The following fields are of main concern:

- Creation of quantity takeoff;

- Creation of budget for construction works;

- Planning/cost management.

The actual information model is crucial for BIM 5D use. It must be created in such a way as to include necessary graphic and non-graphic information about the elements of which it is composed. The level of detail given in this information is usually defined in the standard documents of the appropriate country or as amendments to contract documentation. The CR unfortunately has no such documents and thus clients prepare their own data standards or have to take up foreign standards. Therefore the publication [14] Level of Development (LOD) is used most 
frequently. LOD sets out the level of detail in the information model for different phases of project documentation. LOD thus clearly determines which structures and its parts are to be placed in the model and which are not. Besides the information on graphic processing in the model it also defines those that are non-graphic. The nongraphic information is defined in information modelling as the parameters of an element. These, for example, are data for identifying an element, material, volume, area etc. The detail level scale is from LOD 100 (the lowest detail) up to LOD 500 (the highest detail). The documentation for the building permit is at level LOD 300. Each increase in detail level also raises proportionally the demands factor and how long it takes to create an information model. This consequently also influences the cost per model. Also, a problem arising in the Czech market relates to a shortage of experience that project firms have with modelling higher detail levels of individual structures.

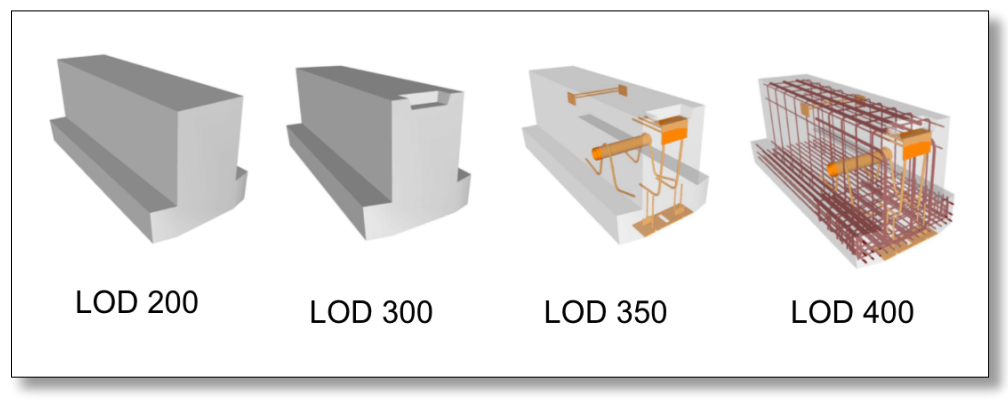

Fig. 2. Graphic representation of detail levels according to LOD [14]

One of the key conditions for the successful interconnection of information modelling and cost management is having an informed specialist with a view of both professional fields in the project team. This fact, according to us, puts a brake on the comprehensive spread of BIM 5D in practice. The given specialist needs to know the current possibilities for creating information models including the supporting software solution and at the same time needs to be aware of demands of the enterprise itself for cost management outputs.

\subsection{Quantity takeoff creation and a budget for construction works with the help of an information model}

Quantity takeoff creation would be significantly more effective and more accurate with the help of data taken from an information model. Currently, programs on the basis of a BIM environment enable extractions with takeoffs on individual elements, but this information about areas and volumes cannot always be adequately used for all types of constructions.

For clear specification of construction elements in a model and consequent creation of quantity takeoffs, along with requirements according to the LOD methodology, there is also crucial non-graphical data on the classification system of the construction output. The classification system allocates to individual construction activities (elements) an identification code, a description, and a method of setting the quantity takeoff in linkage to the unit of measure. Each country usually has its own national classification system or at least a customary structure of building work classification. However, these traditional quantification workbook structures for building output became unusable for modern work with data. This is why these classic quantification workbooks structures have been replaced in a number of countries by new ones such as e.g. in the UK - Uniclass, the USA - OmniClass or Sweden - CoClass. These modern quantification workbooks on structures enable easier classification of the created elements (structures) and for other possibilities of data processing.

In the CR, where there is a strong involvement of the law on public procurement tenders, and along with this the fact that $90 \%$ of linear structures are commissioned by a public client (who has to be in compliance with this standard), there is no motive to create a modern classification system which would respect the local context of the construction market. At present linear structures are mainly procured through a public client by the existing "classical" way inspired by principles based on the Red Book (FIDIC). The original idea behind the Red Book is based on the creation of commission documentation, which contains primarily a technical solution to the project documentation by the investor (client). The given commission documentation also contains the quantity takeoff, defined through a classification system identified as a branch quantification workbook on buildings structures and construction works for over ground road communication (OTSKP). OTSKP is a very specific and unique classification system. OTSKP is not well suited to be used for modern demands of information models in this modified form. 


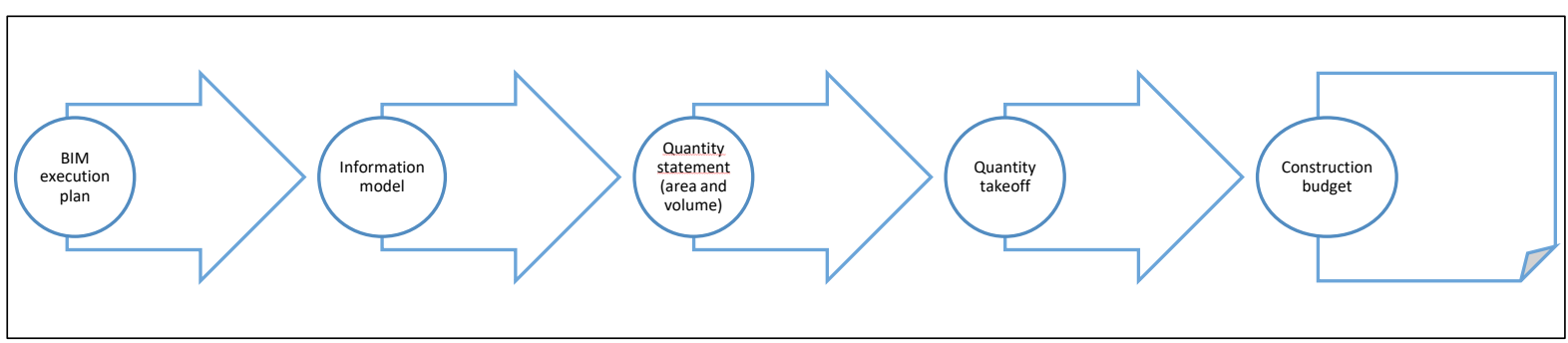

Fig. 3. Scheme of procedure for the creation of a budget of construction works derived from the information model

Fig. 3 shows a method for estimation of a building production. A high quality elaborated BIM execution plan is crucial for the creation of an information model. After creating the information model we take out the information on structures/elements sorted according to the building material with the help of the function quantity takeoff. This extraction will consequently serve as a basis for the creation of quantity takeoffs in the structure of building output classification selected by us. There, after the allocation of building materials to the particular building work (items), we arrive at the quantity takeoffs. Subsequently, the quantity takeoff is brought into software for building production estimation, and there is then reached the allocation of unit and total prices for individual items thus creating a budgetary basis for the construction works.

Even under clearly defined conditions for design managers in the creation of the information model, we will never reach a fully adequate budget of construction works. In order to reach $100 \%$ planned costs from the information model we would also have to include costs which are not directly connected with the project work or information model elements. This would concern cost categories e.g. for deteriorated working conditions, building site installations, other costs etc., where OTSKP has special items for these cost categories. In other countries, these categories of costs are usually broken down into prices for individual building work.

\section{Case study of Highway D11 and D1 reconstruction}

Interconnection of theoretical knowledge with building practice has been implemented through cooperation with two multinational construction companies operating in the Czech market. This has concerned cooperation based on putting forward information models to apply modern technologies for creation of the quantity takeoff and further to budgeting for construction works. On two technically and technologically similar transport projects in particular studies were carried out. The first is an $8 \mathrm{~km}$ long reconstruction of the D11 highway from the Prague ring road in the direction of Hradec Králové. This involves the modernization of a highway which includes complete exchange of pavement layers, connecting the interchanges with the Prague ring road, reconstruction of four bridge structures and repair of drainage and utilities. The second project is a reconstruction of the stretch 06 between the exits 49 Psáre and 56 Soutice on the D1 highway $7.7 \mathrm{~km}$ in length. It involves again the complete reconstruction of pavement, an extension for additional lanes, a highway bridge reconstruction and flyovers including drainage modernization and vegetation improvements. The case study confined itself only to the building activity shared by both projects, namely the exchange of pavement. Contractors (general suppliers) had the information models elaborated for their costs and for their needs. [15,16]

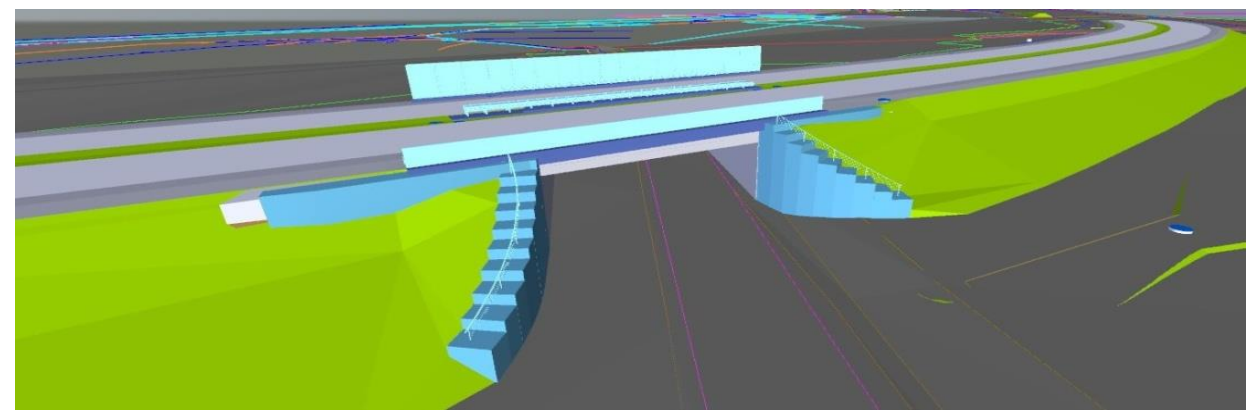

Fig. 4. D11 Highway in the context of BIM 
The use of the information model in both reconstructions is different. With the D11 project the model has been elaborated before starting the building work and serves primarily for quantity takeoffs, survey works, GNSS and UTS heavy machine control systems deployment and quality management and health and safety planning. On the D1 project the information model has been created in the course of the work already started, due to complications on the construction caused by an incorrect elaboration of $2 \mathrm{D}$ project documentation. The level of detail for the elaboration of information models complies with LOD 350 standards, and thus also the documentation for the actual carrying out of the construction.

Table 1. Information on the reconstruction of Highways D11 and D1 [15,16]

\begin{tabular}{lll}
\hline Highways & D11 & D1 \\
\hline Starting & $04 / 2018$ & $03 / 2016$ \\
Ending & $09 / 2019$ & $11 / 2017$ \\
Main route length [m] & 8000 & 7700 \\
Winning bid [CZK] & $787,000,000$ & $929,000,000$ \\
\hline
\end{tabular}

The scheme shown in Fig. 3 will be used for the creation of the quantity takeoff and budget for the construction works. The first step is getting a report on quantity takeoff from an information model which is subsequently transferred into the quantification workbook structures for road construction OTSKP. The transfer to the conferred information models has to be implemented manually due to the absence of code identification of individual elements as the model originators did not embed this data. By this transfer we will get the quantity takeoff which is put into software for assessing construction production, where there are ranked unit and total prices according to the individual construction work. Thus there will be given a basis for the creation of a budget for all the construction work.

Case study results are shown in Fig. 5. From this we can get information on what percentage of total cost we are able to derive from information models currently present in the construction sector. By aggregation (merging) of building works (items) according to desired building sections (Fig.5) there are created OTSKP (e.g. earthworks, foundation constructions etc.). For example, the percentage value of the construction section on earthworks (Tab. 2) is $42 \% .42 \%$ is the portion of earth works budget we are able to take off from the information model. It follows that $42 \%$ of costs tally with the manually created budget for the construction works. This of course means that $58 \%$ of total costs for the building section earthworks we are simply not able to get from the information model. $3 \%$ is set as a maximum limit of permissible difference between the manual and the generated quantity assessment from the information model. If the percentage difference were higher than $3 \%$, the value from the information model would be identified as incorrect and it would not be included in the total assessment.

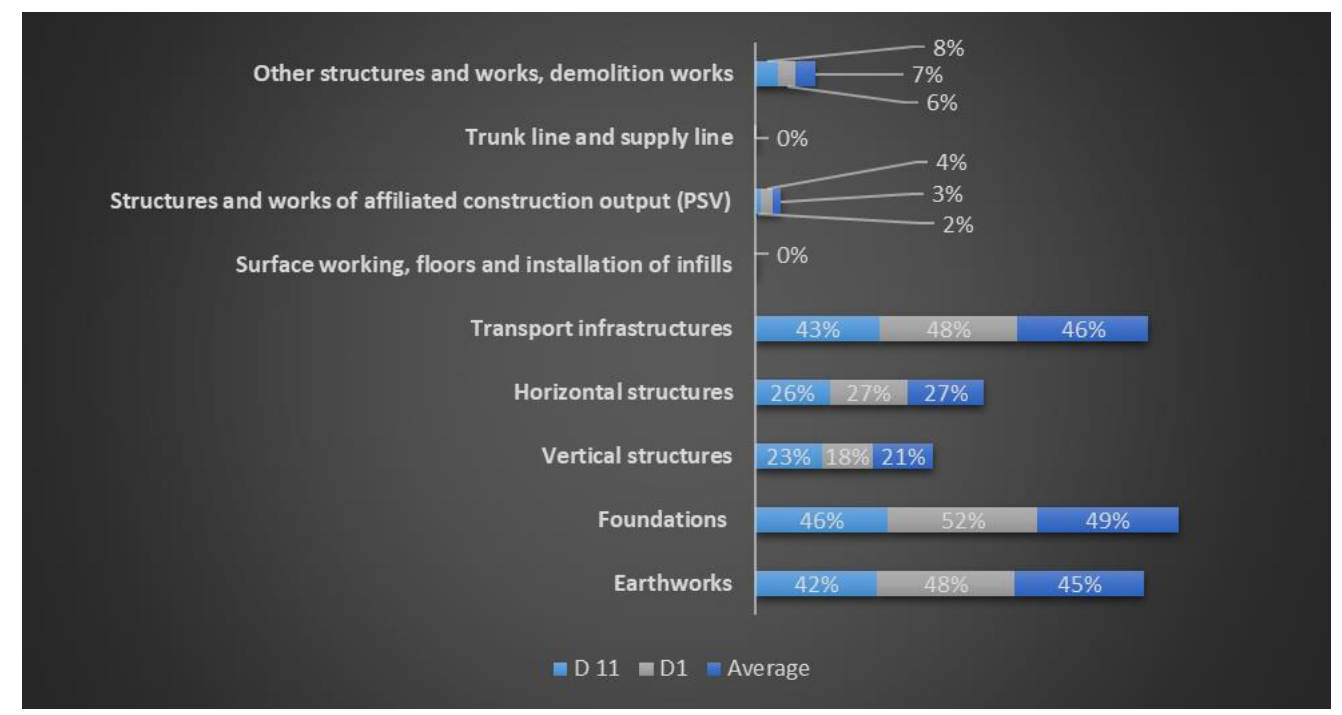

Fig. 5. Result of case study 
Percentage differences between the same construction sections with the Highways D11 and D1 are caused by two factors. The first one is given by the level of detail of the model, despite the fact that both models were in LOD 350 quality. Some constructions were incorrectly drawn and could not be included in the assessment. Furthermore this detail of the model (LOD 350) does not give command in its regulation to draw some elements. Most often these are types of building work involving products used by the ironmonger, plumber and carpenter which are placed in the building section PSV. Building sections with zero percentage value mean that no building activities (items) are used for the highway construction from this section. The building sections for earthworks, foundation constructions and transport infrastructures give very good results. Foundation constructions and road communications contain many items based on volume (concrete, asphalt), and there the quantification from the information model is well achieved. However, in the model for these constructions some elements are absent e.g. formwork which is not drawn into the information model and thus cannot be part of a generated quantity takeoff report. The second factor for the stated difference is caused by minor differences in the work carried out on both highways, even if the projects are similar in terms of pavement reconstruction works.

Table 2. Method of calculating percentage value from total costs for a building section on Highway D11

\begin{tabular}{|c|c|c|c|c|c|}
\hline $\begin{array}{l}\text { Building } \\
\text { section }\end{array}$ & Building activity (item) & $\begin{array}{l}\text { Quantity } \\
\text { takeoff - } \\
\text { manual }\end{array}$ & Quantity takeoff - IM & $\begin{array}{l}\text { Total price } \\
{[\mathrm{CZK}]}\end{array}$ & $\begin{array}{l}\text { Percentage value from total costs for a } \\
\text { building section }\end{array}$ \\
\hline \multirow{5}{*}{ 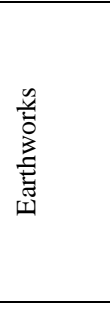 } & $\begin{array}{l}\text { Gravel coarse base } \\
\text { thickness } 150 \mathrm{~mm}\end{array}$ & $1,260 \mathrm{~m}^{2}$ & $190 \mathrm{~m}^{3}$ & 475,300 & 3,80 \\
\hline & $\begin{array}{l}\text { Asphalt concrete back coat } \\
\text { ACP } 22 \text { thickness } 60 \mathrm{~mm}\end{array}$ & $980 \mathrm{~m}^{2}$ & $59 \mathrm{~m}^{3}$ & 118,000 & 0,95 \\
\hline & Dry hydrate & $15,2 \mathrm{t}$ & $\begin{array}{l}\text { - (in IM connected } \\
\text { with another element) }\end{array}$ & - & - \\
\hline & $\ldots($ next items $)$ & $\cdots$ & $\ldots$ & $\cdots$ & $\ldots$ \\
\hline & \multicolumn{3}{|c|}{ Sum for a building section (earthworks) } & $5,264,700$ & 42,05 \\
\hline
\end{tabular}

The total average percentage value for all building sections is $28 \%$. This means that we are already capable of getting from the information model data $28 \%$ of the total cost for a construction project. In view of the fact that in the CR information modelling with linkage to cost management is just starting to be formulated, it can be stated that the given findings bring confidence for increased efficiency in budgeting for construction works.

\section{Conclusion}

Current possibilities for the use of information modelling in the estimation of construction production have been verified in the chapter named Case study of the reconstruction of highways D11 and D1. Information models on reconstruction of highways D11 and D1 are stated as the latest current ones, and these are being used in actual construction and thus they represent the current BIM quality available in the Czech construction market. From the conducted research it has been asserted that with the help of generated data there can be gained on average $28 \%$ of the cost for construction activity. This confirms the increasing level of detail in information models and their subsequent use for further construction segments such as e.g. cost management. Unfortunately, in information models there appeared structural mistakes which made some generated takeoffs unusable. Minor differences also appeared in the level of model processing, where the models were processed by two different Offices, even if they had to be created to the same standard LOD 350. It is supposed that these mistakes will be omitted with the use of a BIM Execution Plan thoroughly specifying rules for quantity take offs.

In information models there has not been used any classification of construction production which would subsequently facilitate work with the extracted data. In the CR, according to the valid legislation for the classification of road construction production, there has to be used the quantification workbook structure OTSKP which, due to its origins in the 1960 's, does not meet modern requirements on data analysis. In order to increase the working efficiency of these information models they must be modified or left aside as has already happened abroad.

The BIM execution plan is the crucial document for the possibility of embedding cost management into information modelling. This document must be created precisely so that the resulting information model can be put to the best possible use. The level of model detail plays a big role here. Given the non-existence of localized Czech 
standards for BIM, the standards specification usually refers back to foreign specifications LOD where the currently used detail LOD 350 seems optimal from the viewpoint of creating a quantity takeoff/budget for construction works. However, all the regulations determined by this standard must be fulfilled so that there does not arise structural errors and there is no placing together of different materials.

The disadvantage in the CR still lies in the low level of knowledge and awareness on the side of construction companies and design companies regarding the current possibilities for BIM. Broader utilization is limited to willingness to address some potentially considerable investment into software and business analytics. In our national situation it is mostly architects who are working with a model based on 3D models utilizing BIM models to prepare sketches and visualizations. There is usually no further continuation with a primary model created in such a way going towards more detailed levels of project documentation. Companies with multinational operations are driving the change in this environment. The national CR legal situation is weighted against the development of projects based on BIM for use in public procurement tenders, and thus on projects related to transport and road infrastructure. From the clients prospective SFTI is driving the change towards a digital and more efficient environment.

\section{Acknowledgements}

This work was supported by the Grant Agency of the Czech Technical University in Prague, grant No. SGS18/023/OHK1/1T/11.

\section{References}

[1] Horelica, Z., Mertlova, O., Vykydal, I. \& Zak, J. (2017). "Využití digitálních metod a zavedení informačního modelování staveb jako nástroj k dosažení vyšší efektivnosti staveb financovaných Státním fondem dopravní infrastruktury.” Silnice a Železnice, no. 1.

[2] Horelica, Z., Mertlova, O., Vykydal, I. \& Zak, J. (2017). "Plán pro využití digitálních metod a zavedení informačního modelování staveb" Státní fond dopravní infrastruktury.

[3] Zak, J. \& Vitasek, S. (2018) „BIM a Superior Approach for Infrastructure Construction in the Czech Republic“ Submitted to Engineering for Rural Development, Jelgava.

[4] Matejka, P., Kosina, V., Tomek, A., Tomek, R., Berka, V. \& Sulc, D. (2016) “The Integration of BIM in Later Project Life Cycle Phases in Unprepared Environment from FM Perspective". Paper presented at the Procedia Engineering, 164 550-557. 10.1016/j.proeng.2016.11.657.

[5] Bouska, R. \& Schneiderová Heralova, R. (2017). "Opportunities for use of Advanced Visualization Techniques for Project Coordination". Paper presented at the Procedia Engineering, 196 1051-1056. 10.1016/j.proeng.2017.08.061.

[6] Smith, P. (2016). "Project cost management with 5D BIM". Paper presented at the Procedia Engineering, $226193-200$. 10.1016/j.sbspro.2016.06.179.

[7] Xu, J. (2016). "Research on Application of BIM 5D Technology in Central Grand Project". Paper presented at the Procedia Engineering, 174 600-610. 10.1016/j.proeng.2017.01.194.

[8] Minagawa, M., \& Kusayanagi, S. (2015). "Study on BIM utilization for design improvement of infrastructure project." Paper presented at the Procedia Engineering, 125 431-437. 10.1016/j.proeng.2015.11.113.

[9] Olsen, D., \& Taylor, M. (2017). "Quantity Take-Off Using Building Information Modeling (BIM), and Its Limiting Factors.” Paper presented at the Procedia Engineering, 196 1098-1105. 10.1016/j.proeng.2017.08.067

[10] Vitasek, S., \& Matejka, P. (2017). "Utilization of BIM for automation of quantity takeoffs and cost estimation in transport infrastructure construction projects in the Czech Republic". Paper presented at the IOP Conference Series: Materials Science and Engineering, 236(1)10.1088/1757-899X/236/1/012110.

[11] Plebankiewicz, E., Zima, K. \& Skibniewski, M. (2015). “Analysis of the First Polish BIM-Based Cost Estimation Application”. Paper presented at the Procedia Engineering, 123 405-414. 10.1016/j.proeng.2015.10.064.

[12] Bouska, R. (2016). "Evaluation of Maturity of BIM Tools across Different Software Platforms". Paper presented at the Procedia Engineering, 164 481-486. 10.1016/j.proeng.2016.11.648.

[13] Zak, J., \& Macadam, H. (2017). "Utilization of building information modeling in infrastructure's design and construction." IOP Conf. Ser.: Mater. Sci. Eng. 236 012108, BESTInfra 2017, doi:10.1088/1757-899X/236/1/012108.

[14] Areo blog - Lifecycle BIM and smart FM [online]. 2018 [cit. 2018-04-05]. Available from: http://blog.areo.io/content/images/2016/12/LEDBIM-example.png.

[15] Czech state highway agency: Highway D11 [online]. 2018 [cit. 2018-04-05]. Available from: https://www.rsd.cz/wps/portal/web/mapaprojektu/\#/opravy?filters[]=Realizace

[16] Czech state highway agency: Highway D1 [online]. 2018 [cit. 2018-04-05]. Available from: https://www.rsd.cz/wps/portal/web/mapaprojektu/\#/opravy?filters[]=Realizace 